\title{
AN EXPERIMENT ON IMAGE TRANSMISSION TO AN ICEBREAKER
}

\section{(Abstract)}

by

O. Korhonen

(Asiakkaankatu 3A, PL 33, 00937 Helsinki, Finland)

\section{ABSTRACT}

Finland has such a climate that all its harbours in the Baltic Sea are frozen every winter. Ice may sometimes be more than $1 \mathrm{~m}$ thick, as it was in the Bay of Bothnia, the northernmost basin of the Baltic Sea, during the winter of 1985.

The Finnish Institute of Marine Research has used the imagery of the Tiros- $\mathrm{N}$ series of satellites successfully in sea-ice mapping for some years. In the Institute daily ice charts have been prepared and sent by facsimile to icebreakers in the Baltic Sea. In 1985, an experiment was conducted to transmit the same imagery to an icebreaker operating in the Bay of Bothnia. Existing telecommunication networks were used. The image data transmitted by NOAA-6 and NOAA-9 satellites were received at Tromsø Telemetry Station in Norway and then transmitted to Espoo in Finland. The data processing consisted of geometric correction, edge enhancement, and drawing the coastline with location symbols. The most interesting area was extracted and transmitted by NMT mobile telephone to the icebreaker.

The almost real-time image transmission turned out to be useful from the point of view of icebreaker operation. The images could be used to identify cracks and narrow leads in the ice. Such very detailed information cannot be included in routine ice charts. The icebreaker can use this information for giving instructions to other ships to find easier routes. This reduces the need for icebreaker assistance. The images can also help the icebreaker to avoid wide heavily ridged areas.

This experiment was at low cost and can be technically developed further. It showed that this kind of assistance for icebreakers is economically profitable for winter navigation.

\section{SPECTRAL RESPONSE PATTERNS OF SNOW AND ICE SURFACES FOR THE LANDSAT MULTISPECTRAL SCANNER}

\author{
(Abstract) \\ by \\ M. Kristensen \\ (Norwegian Meteorological Institute, 0314 Oslo 3, Norway) \\ and \\ N.F. McIntyre
}

(Mullard Space Science Laboratory, University College London, Dorking, Surrey RH5 6NT, U.K.)

\begin{abstract}
The high-resolution imagery recorded by systems such as the multi-spectral scanners (MSSs) of the Landsat satellites has revolutionized the study of all types of surface in the polar regions. Visible and near-infra-red imagery has found a wide range of glaciological uses. There is, however, a lack of comparability within and between MSS data which may be a contributary factor to some current problems in interpretation of remotely sensed glaciological data.

With the expected continuity of MSS coverage for the forseeable future, it is highly desirable to extend use of the data beyond the basic mapping and feature identification which has made it such a valuable resource. One of the most obvious developments is to investigate characteristics of the reflecting surfaces and to achieve absolute identification of snow and ice surfaces. Although conversion of digital MSS grey tones to radiances enables direct comparison with
\end{abstract}

other sources, automatic identification requires detailed and extensive knowledge of the spectral and reflecting characteristics of surfaces which are to be monitored. This is of ten best achieved through ground-based observation.

In order to provide a base line against which corrected radiances from Landsat MSS data can be compared, a spectrally gated photometer has been used to measure albedo at MSS wave bands in a wide range of conditions. The surfaces monitored in several parts of Norway include sea ice, lake ice, snow, firn and glacier ice, permafrost, and reference surfaces. A range of supporting measurements (including grain-size, surface irregularity, density, level, and free-water content) allows accurate characterization of each surface. This enables identification of spectral-response patterns for each surface category and hence the classification of their reflectances as recorded by the MSS. Examples are given of the application of such classifications to imagery of the polar regions. 